\title{
Role of Pre-Operative of Neutrophil/Lymphocyte and Platelet/Lymphocyte Ratio in Prognosis of Hepatocellular Carcinoma
}

\author{
Chen-Guo Ker ${ }^{1 *}$, Hong-Yi Tong ${ }^{1}$, Ming-Yuen Yang1, I-Tsou Tseng1, Der-Ming Chang ${ }^{1}$, \\ Hong-Yaw Chen', Bo-Wei Wang' ${ }^{2}$, Chiu-Man $\mathrm{Ko}^{2}$, Chin-Yi Chao' ${ }^{2}$, Yu-Fu Chen ${ }^{3}$ \\ ${ }^{1}$ Department of Digestive Surgery, Yuan's General Hospital, Taiwan \\ ${ }^{2}$ Department of Cancer Resource Cancer, Yuan's General Hospital, Taiwan \\ ${ }^{3}$ Department of Medical Education and Research, Yuan's General Hospital, Taiwan \\ Email: *kercg@yuanhosp.com.tw
}

How to cite this paper: Ker, C-G, Tong, H-Y, Yang, M-Y, Tseng, I-T, Chang, D-M, Chen, H-Y, Wang, B-W, Ko, C-M, Chao, C-Y and Chen, Y-F (2020) Role of Pre-Operative of Neutrophil/Lymphocyte and Platelet/Lymphocyte Ratio in Prognosis of Hepatocellular Carcinoma. International Journal of Clinical Medicine, 11, 491-503.

https://doi.org/10.4236/ijcm.2020.119042

Received: June 24, 2020

Accepted: August 28, 2020

Published: August 31, 2020

Copyright $\odot 2020$ by author(s) and Scientific Research Publishing Inc. This work is licensed under the Creative Commons Attribution International License (CC BY 4.0).

http://creativecommons.org/licenses/by/4.0/

\section{(c) (i) Open Access}

\begin{abstract}
Introduction: Hepatocellular carcinoma (HCC) has a poor prognosis and is ranked in the top 2 leading causes of death in Taiwan. The clinical features which affect survival rate should be noticed for alarming. We tried to study the neutrophil-lymphocyte ratio (NLR) and platelet-lymphocyte ratio (PLR) for the predictor of prognosis of HCC. Patients and Methods: A total of 525 patients with HCC were undergone surgical or non-surgical treatment registered in Cancer Registry Center of our hospital. The clinical features included patient's basic profiles, and neutrophil, lymphocyte and platelet count in the peripheral blood at the time of diagnosis. The ratio of neutrophil/lymphocyte and platelate/lymphocyte was measured and their survival rates were analyzed based on their ratio scales. Results: Three scales of NLR and PLR were $\leq 1.62,1.63-2.57, \geq 2.58$ and $\leq 224,225-253, \geq 254$ respectively. Either higher NLR $\geq 2.58$ or higher PLR $\geq 254$ was found mostly in the male and TMN stage III and IV with a significant difference $(\mathrm{P}<0.01)$. The 5-year survival rates of NLR $\leq 1.62,1.63-2.57, \geq 2.58$ were $33.9 \%, 33.7 \%$, and $16.7 \%$ respectively $(\mathrm{P}<0.001)$. The mean survival times were $34.1 \pm 1.4,29.3 \pm 8.1$, and $14.2 \pm 2.1$ months for the scales of PLR $\leq 224,225-253$, and $\geq 254$ respectively. The 5 -year survival rates were $25.5 \%, 36.4 \%$, and $7.7 \%$ for the groups of the PLR $\leq 224,225-253$, and $\geq 254$ respectively ( $<<0.001)$. Conclusion: Neutrophil, lymphocyte and platelet are players in cancer growth and have a potential role as predictors of survival in our HCC patients. Therefore, we should pay more attention to the higher NLR or PLR which will result in a poorer prognosis in our patients.
\end{abstract}




\section{Keywords}

Neutrophil, Lymphocyte, Platelet, Liver Cancer, Prognosis

\section{Introduction}

HCC had been ranked as the 2nd leading cause of cancer death in Taiwan for several years [1]. Most oncologists try to get a good survival due to the improvement of care program in the world [2] [3]. Pretreatment imaging and assessment remain the main methods used to evaluate prognosis in liver cancer patients after treatments [4] [5] [6]. The relationship of the prognosis of HCC patients and inflammation was noted in recent decade [4] [7] [8].

Inflammation is an important component of tumor progression which had been mentioned for decades. It is well known that major liver cancer develops during inflammatory reaction of hepatitis B or C virus infection [9] [10]. Tumor micro-environment regulated by inflammatory cells clearly plays a basic role in the neoplastic process, stimulation of proliferation and migration and survival [11] [12] [13]. The inflammatory reaction usually responds to tumors persistence. Tumor cells produce various cytokines and chemokines that attract leukocytes. The inflammatory component of a developing neoplasm may include a diverse leukocyte population such as neutrophils, macrophages, and lymphocytes [12] [14].

Platelets can release granules containing a variety of contents that can both inhibit and stimulate plasmatic coagulation, angiogenesis immune-surveillance, or neoplasm growth through the releasing growth factors such as platelet derived growth factor, platelet factor IV and thrombospondin [15] [16]. Therefore, platelets can play important roles in tumor pathophysiology, including immune escape in hematogenous tumor spread and leading to tumor cell adhesion, invasion and tumor progression. In the previous reports, good or poor predictor of survival with neutrophil-lymphocyte ratio (NLR) or platelet-lymphocyte ratio (PLR) was demonstrated in some solid tumors such as liver, colo-rectum, breast, lung, and cervical cancers [17] [18] [19] [20] [21]. The prognostic potential of a novel inflammation-based system, the combination of the NLR and PLR, for predicting the survival time of 287 patients with HCC who had an elevated NLR $(>2.58)$ and an elevated PLR $(>131.78)$ were allocated an important prognostic score [22]. In addition to clinical grading scales of HCC, NLR or PLR could be used for demonstrating that patients with HCC have a significantly high risk of progressive disease following initial treatments [23] [24]. Therefore, we try to study the roll of NLR and PLR scales in the predictor of prognosis of HCC patients.

\section{Patients and Methods}

There were a total of 653 HCC patients registered in Cancer Registry Center of 
our hospital from 2010 to 2014 . Among them, 525 patients with complete data were enrolled in this study and there were 371 (70.7\%) male and 154 (29.3\%) female. All patients were confirmed diagnosis based on the cancer treatment guideline from our Cancer Registration Center. There were 131 (24.9\%) and 394 (75.1\%) patients initially underwent surgical and non-surgical treatments in our series. The non-surgical treatment included trans-arterial chemo-embolization (TACE), hepatic artery chemo-infusion (HAI), percutanous ethanol injection (PEI) or radio-frequency ablation (RFA) based on our hospital treatment guideline. The clinical features include patient's basic profiles, and neutophil, lymphocyte and platelet count in the peripheral blood at the time of diagnosis. The optimal cut-off from normal range of leukocyte, neutrophil \& lymphocyte, and platelet were 4000 - 10,000/dl, 43\% - 71\% \& 16.7\% - 43.4\%, and 150,000 $440,000 / \mathrm{dl}$ respectively, the scale of NLR and PLR were derived from the lower normal range and higher normal range in cell number for neutrophil, lymphocyte and platelet. The 3 scales of NLR and PLR were $\leq 1.62,1.63-2.57, \geq 2.58$ and $\leq 224,225$ - 253, $\geq 254$ respectively. The 1-, 3-, and 5-year survival rates were analyzed.

These results are presented as mean \pm SD and Kaplan-Meier analysis for their survival rates. Statistical analysis was performed with an unpaired Student's t-test after ANOVA for more than the other two groups in liver cancer patients. The P-values less than 0.05 were considered to be significant.

\section{Results}

1) General profiles of the patients of three scales of NLR

Three scales of NLR of HCC patients and their basic profiles were listed in Table 1. Relatively poor survival was found to be in the scale of higher NLR. Higher NLR was found mostly in the male $(248,74.5 \%)$ and TMN stage III and IV with a significant difference $(\mathrm{P}<0.01)$. Surgical treatment was underwent more in the patients of low NLR ( $\mathrm{n}=26,36.6 \%$ vs $\mathrm{n}=299,79.9 \%, \mathrm{P}<0.002)$.

The number of death was $262(78.7 \%)$ in the higher NLR $\geq 2.58$ with poor prognosis compared to other scales as shown in Table $1 \&$ Table 2 . The survival curves demonstrated poorer prognosis of HCC patients in Figure 1. The mean survival times were $44.3 \pm 3.2,40.4 \pm 2.6$, and $24.1 \pm 1.4$ months for the scales of the NLR $\leq 1.62,1.63-2.57$, and $\geq 2.58$ respectively. The 5-year survival rates were $33.9 \%, 33.7 \%$, and $16.7 \%$ respectively $(\mathrm{P}<0.001)$. If NLR was more than 2.58 , the 5 -year survival rate was shorter than that of the other two groups $(\mathrm{P}=$ $0.001)$.

2) General profiles of the patients of three scales of PLR

Basic profiles of three scales of PLR of liver cancer patients were listed in Table 3. Relative poor survival was found in the scale of higher PLR. Higher PLR $\geq$ 254 were found mostly in the male $(62,69.7 \%)$ and TMN stage III and IV ( $\mathrm{n}=$ $68,77.3 \%)$ with a significant difference $(\mathrm{P}<0.01)$. Surgical treatment was performed in the patients of PLR $\leq 224(\mathrm{n}=113,26.6 \%)$ and PLR $\geq 254(\mathrm{n}=15$, $16.9 \%)$ without significant difference $(\mathrm{P}=0.153)$. 
Table 1. Basic profiles of patients divided by three scales of NLR.

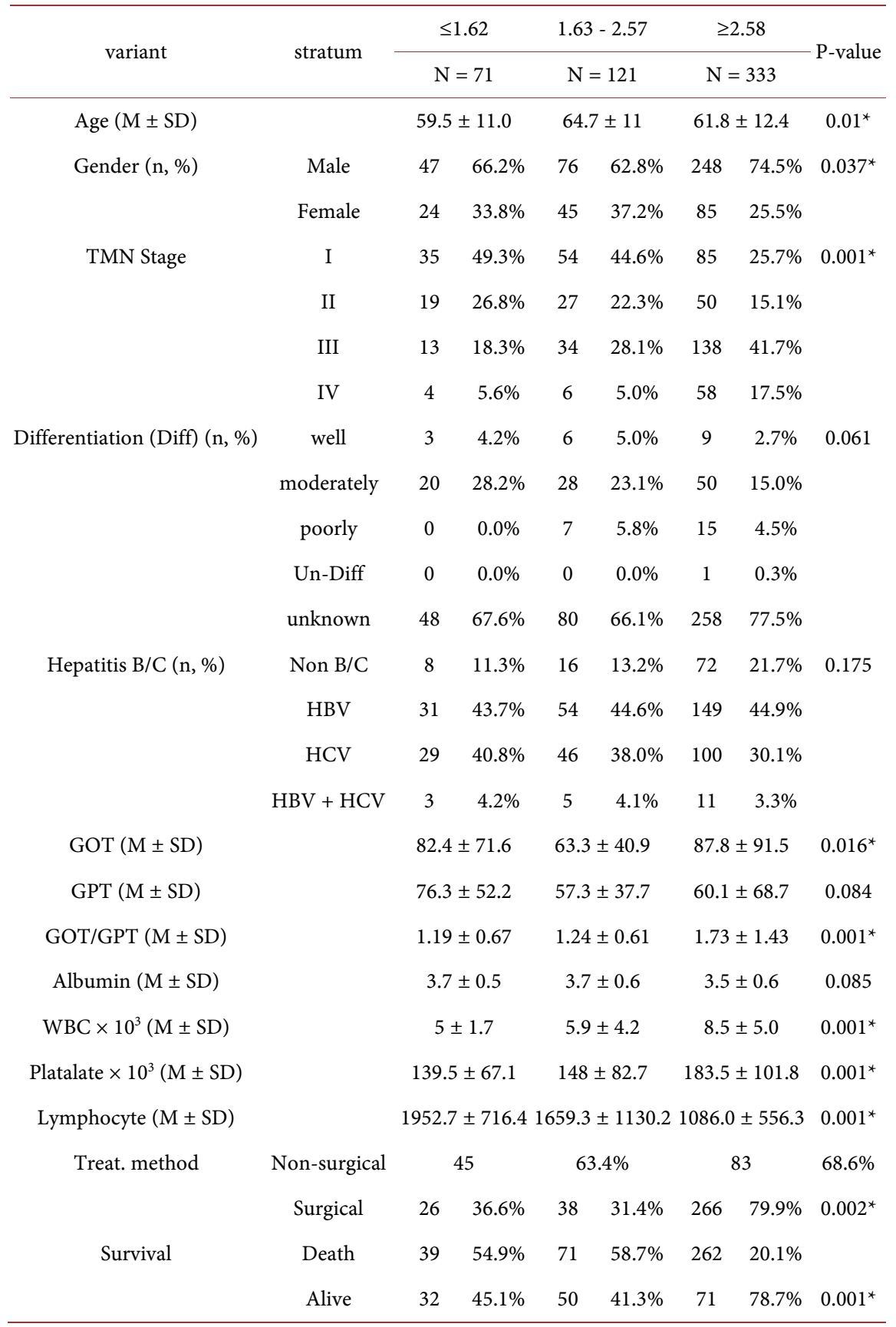

${ }^{*} \mathrm{P} \leq 0.05$.

Table 2. Survival rate based on the scale of N/L ratio of liver cancer.

\begin{tabular}{cccccccc}
\hline \multirow{2}{*}{$\mathrm{N} / \mathrm{L}$} & \multirow{2}{*}{$\mathrm{n}$} & \multirow{2}{*}{ Death } & \multicolumn{2}{c}{ Survival (Month) } & \multicolumn{3}{c}{ Survival (\%) } \\
\cline { 5 - 8 } & & & Mean & $\mathrm{SD}$ & $1 \mathrm{yr}$ & $3 \mathrm{yr}$ & $5 \mathrm{yr}$ \\
\hline$\leq 1.62$ & 71 & $39(54.9 \%)$ & 44.3 & 3.2 & 80.3 & 60.3 & 33.9 \\
$1.63-2.57$ & 121 & $71(58.6 \%)$ & 40.4 & 2.5 & 76.9 & 49.4 & 33.7 \\
$\geq 2.58$ & 333 & $262(78.7 \%)^{*}$ & 24.1 & 1.4 & 50.8 & 25.8 & 16.7 \\
\hline${ }^{* \mathrm{P}<0.001 .}$ & & & & & & &
\end{tabular}


Table 3. Basic profiles of patients divided by three scales of PLR.

\begin{tabular}{|c|c|c|c|c|c|c|c|c|}
\hline \multirow{2}{*}{ variant } & \multirow{2}{*}{ stratum } & \multicolumn{2}{|c|}{$\leq 224$} & \multicolumn{2}{|c|}{$225-253$} & \multicolumn{2}{|c|}{$\geq 254$} & \multirow{2}{*}{ P-value } \\
\hline & & \multicolumn{2}{|c|}{$\mathrm{N}=425$} & \multicolumn{2}{|c|}{$\mathrm{N}=11$} & \multicolumn{2}{|c|}{$\mathrm{N}=89$} & \\
\hline \multicolumn{2}{|l|}{ Age $(\mathrm{M} \pm \mathrm{SD})$} & \multicolumn{2}{|c|}{$61.9 \pm 0.6$} & \multicolumn{2}{|c|}{$64.7 \pm 2.2$} & \multicolumn{2}{|c|}{$63.1 \pm 12.9$} & 0.529 \\
\hline \multirow[t]{2}{*}{ Gender (n, \%) } & Male & 229 & $70.4 \%$ & 10 & $90.9 \%$ & 62 & $69.7 \%$ & 0.327 \\
\hline & Female & 126 & $29.6 \%$ & 1 & $9.1 \%$ & 27 & $30.3 \%$ & \\
\hline \multirow[t]{4}{*}{ TMN Stage } & I & 158 & $37.3 \%$ & 3 & $27.3 \%$ & 13 & $14.8 \%$ & $0.001^{*}$ \\
\hline & II & 89 & $21.0 \%$ & 0 & $0.0 \%$ & 7 & $8.0 \%$ & \\
\hline & III & 127 & $30.0 \%$ & 7 & $63.6 \%$ & 51 & $58.0 \%$ & \\
\hline & IV & 50 & $11.8 \%$ & 1 & $9.1 \%$ & 17 & $19.3 \%$ & \\
\hline \multirow[t]{5}{*}{ Differentiation (Diff) (n, \%) } & well & 15 & $3.5 \%$ & 0 & $0.0 \%$ & 3 & $3.4 \%$ & $0.001^{*}$ \\
\hline & moderately & 84 & $19.8 \%$ & 2 & $18.2 \%$ & 12 & $13.5 \%$ & \\
\hline & poorly & 19 & $4.5 \%$ & 0 & $0.0 \%$ & 3 & $3.4 \%$ & \\
\hline & Un-Diff & 0 & $0.0 \%$ & 1 & $9.1 \%$ & 0 & $0.0 \%$ & \\
\hline & unknown & 307 & $72.2 \%$ & 8 & $72.7 \%$ & 71 & $79.8 \%$ & \\
\hline \multirow[t]{4}{*}{ Hepatitis B/C (n, \%) } & Non B/C & 68 & $16.0 \%$ & 2 & $20.0 \%$ & 26 & $29.2 \%$ & 0.121 \\
\hline & $\mathrm{HBV}$ & 194 & $45.6 \%$ & 4 & $40.0 \%$ & 36 & $40.4 \%$ & \\
\hline & $\mathrm{HCV}$ & 147 & $34.6 \%$ & 3 & $30.0 \%$ & 25 & $28.1 \%$ & \\
\hline & $\mathrm{HBV}+\mathrm{HCV}$ & 16 & $3.8 \%$ & 1 & $10.0 \%$ & 2 & $2.2 \%$ & \\
\hline GOT $(\mathrm{M} \pm \mathrm{SD})$ & & \multicolumn{2}{|c|}{$77.8 \pm 3.8$} & \multicolumn{2}{|c|}{$55 \pm 10.5$} & \multicolumn{2}{|c|}{$101.8 \pm 9.3$} & $0.021^{*}$ \\
\hline $\mathrm{GPT}(\mathrm{M} \pm \mathrm{SD})$ & & \multicolumn{2}{|c|}{$63 \pm 3.1$} & \multicolumn{2}{|c|}{$46.2 \pm 13.3$} & \multicolumn{2}{|c|}{$56.9 \pm 5.3$} & 0.482 \\
\hline GOT/GPT $(\mathrm{M} \pm \mathrm{SD})$ & & \multicolumn{2}{|c|}{$1.40 \pm 0.05$} & \multicolumn{2}{|c|}{$1.65 \pm 0.62$} & \multicolumn{2}{|c|}{$2.25 \pm 0.20$} & $0.001^{*}$ \\
\hline Albumin $(\mathrm{M} \pm \mathrm{SD}$ & & \multicolumn{2}{|c|}{$3.6 \pm 0.0$} & \multicolumn{2}{|c|}{$3.8 \pm 0.2$} & \multicolumn{2}{|c|}{$3.3 \pm 0.1$} & $0.001^{\star}$ \\
\hline $\mathrm{WBC} \times 10^{3}(\mathrm{M} \pm \mathrm{SD})$ & & \multicolumn{2}{|c|}{$7.0 \pm 0.2$} & & \pm 1.2 & & \pm 0.6 & $0.001^{\star}$ \\
\hline Platalate $\times 10^{3}(\mathrm{M} \pm \mathrm{SD})$ & & 143. & \pm 3.3 & 221 & \pm 32.9 & 280. & \pm 12.4 & $0.001^{*}$ \\
\hline Neutrophi $(M \pm S D)$ & & 4697 & \pm 181 & 6131 & \pm 1107 & 7972. & \pm 543.2 & $0.001^{*}$ \\
\hline Lymphocyte $(\mathrm{M} \pm \mathrm{SD})$ & & 1474. & \pm 40.3 & 903. & \pm 129.8 & 713 & 41.2 & $0.001^{*}$ \\
\hline Treat. method & Non-surgical & 312 & $73.4 \%$ & 8 & $72.7 \%$ & 74 & $83.1 \%$ & 0.153 \\
\hline & Surgical & 113 & $26.6 \%$ & 3 & $27.3 \%$ & 15 & $16.9 \%$ & \\
\hline Survive & Death & 286 & $67.3 \%$ & 7 & $63.6 \%$ & 80 & $89.9 \%$ & $0.001^{*}$ \\
\hline & Alive & 139 & $32.7 \%$ & 4 & $36.4 \%$ & 9 & $10.1 \%$ & \\
\hline
\end{tabular}

${ }^{*} \mathrm{P} \leq 0.05$.

In the period of 5 years follow-up study, the number of death was 80 (89.9\%) patients in the scale of PLR $\geq 254$ with poorer prognosis compared to other scales as shown in Table $3 \&$ Table 4 . The survival curves demonstrated poorer prognosis of HCC patients with PLR $\geq 254$ shown in Figure 2. The mean survival times were $34.1 \pm 1.4,29.3 \pm 8.1$, and $14.2 \pm 2.1$ months for the groups of the PLR $\leq 224,225-253$, and $\geq 254$ respectively. The 5-year survival rates were $25.5 \%, 36.4 \%$, and $7.7 \%$ for the groups of the PLR $\leq 224,225-253$, and 


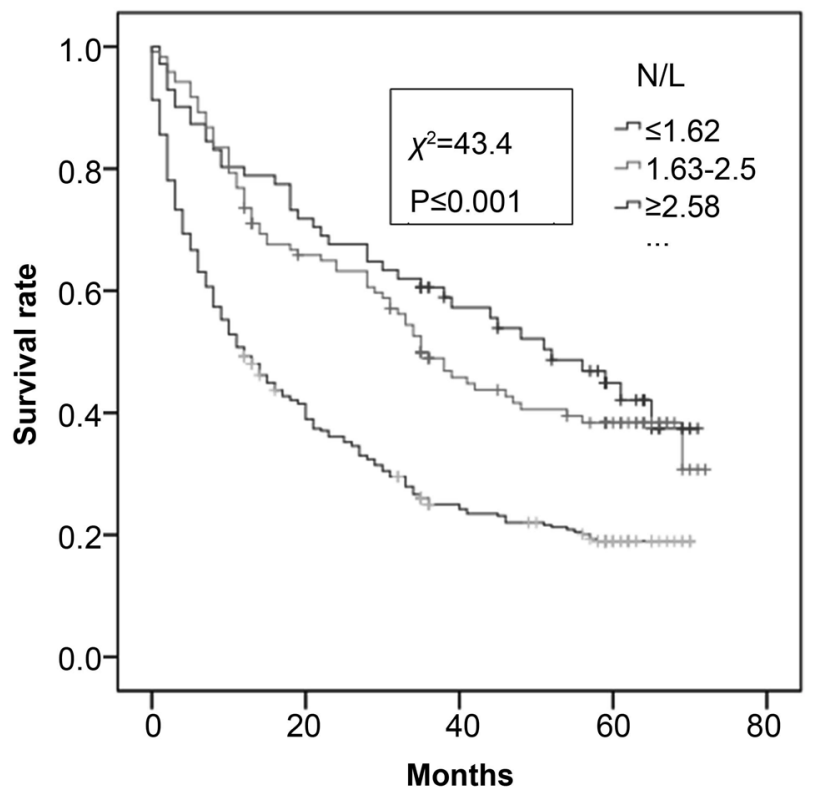

Figure 1. Survival cure of liver cancer patients based on the scale of N/L ratio and high ratio had a poor prognosis $\left(\chi^{2}=43.4, \mathrm{P} \leq 0.001\right)$.

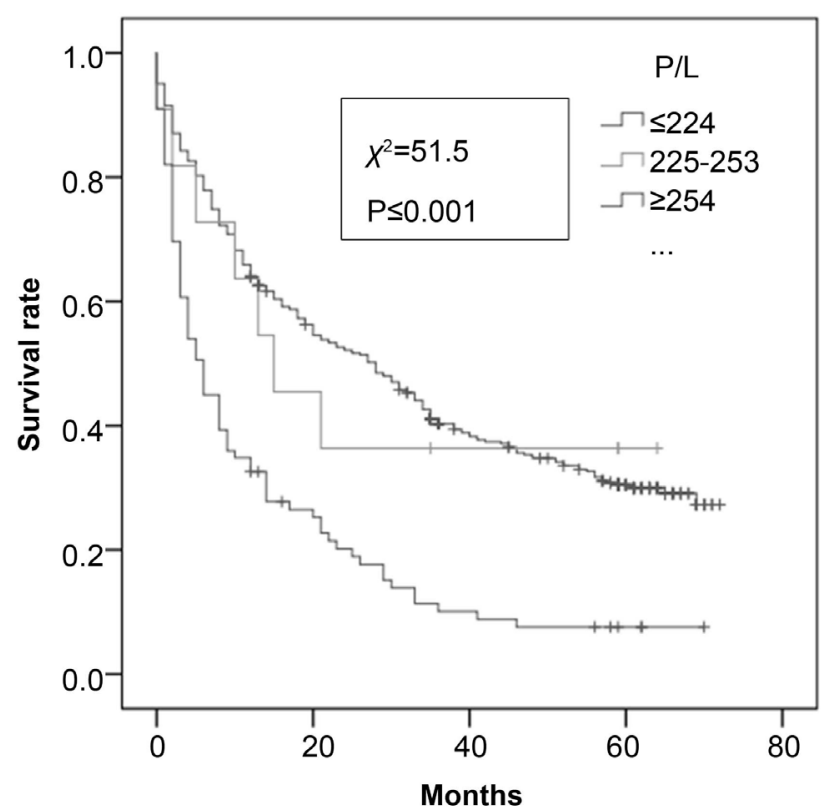

Figure 2. Survival cure of liver cancer patients based on the scale of $\mathrm{P} / \mathrm{L}$ ratio and high ratio had a poor prognosis $\left(\chi^{2}=51.5, \mathrm{P} \leq 0.001\right)$.

Table 4. Survival rate based on the scale of $\mathrm{P} / \mathrm{L}$ ratio of liver cancer

\begin{tabular}{cccccccc}
\hline \multirow{2}{*}{$\mathrm{P} / \mathrm{L}$} & $\mathrm{n}$ & Death $\mathrm{n}$ & \multicolumn{2}{c}{ Survival (Month) } & \multicolumn{3}{c}{ Survival (\%) } \\
\cline { 4 - 8 } & & & Mean & SD & $1 \mathrm{yr}$ & $3 \mathrm{yr}$ & $5 \mathrm{yr}$ \\
\hline$\leq 224$ & 425 & 286 & 34.1 & 1.4 & 65.9 & 40.5 & 25.5 \\
$225-253$ & 11 & 7 & 29.3 & 8.1 & 63.6 & 36.4 & 36.4 \\
$\geq 254$ & 89 & 80 & 14.2 & 2.1 & 34.8 & 11.6 & 7.7 \\
\hline
\end{tabular}


$\geq 254$ respectively $(\mathrm{P}<0.001)$. The results of higher $\mathrm{PLR} \geq 254$ could reflect poorer survival more solitary than that of higher NLR $\geq 2.58$ as shown in Table 1 \& Table 3, and Figure 1 \& Figure 2.

\section{Discussion}

Clinical features and molecular pathology of HCC are the main determinants of current treatment strategies and prognosis factors. The relationship between the inflammatory cells and cancer has been demonstrated by accumulating studies [11]. The counts of peripheral inflammatory cells, including neutrophil, lymphocyte and platelet, have demonstrated the strong link between the inflammatory system and prognosis in cancer patients [6] [10]. In particular, NLR and PLR have recently been reported to be prognostic factors in several types of solid cancers [17] [18] [19] [20] [21].

Early in the neoplastic process, these inflammatory cells are powerful tumor promoters, facilitating genomic instability and promoting angiogenesis. The inflammatory cells produced chemokines and cytokines that influenced the whole tumor mass, regulating the growth, migration and differentiation of all cell types in the tumor micro-environment [11] [14]. In addition, these inflammatory cells will release growth factors, promoting angiogenesis and lymphangiogenesis, stimulating DNA damage, remodelling the extra-cellular metaprotease to facilitate invasion, coating tumour cells to make available receptors for disseminating cells via lymphatics and capillaries, and evading host defense mechanisms. In fact, excess inflammatory cells in the tumor microenvironment which harbor risk for developing cancer or are indicators of prognosis in a fully developed malignancy [11] [13] [25].

The role of neutrophils in cancer usually reflects a state of host inflammation, which is a hallmark of cancer. They can participate in different stages of the oncogenic process including tumor initiation, growth, proliferation or metastasis [13] [26] [27]. In patients with solid cancers, neutrophils expand both locally at the tumor microenvironment and systemically, the expansion of neutrophil is generally associated with poor prognosis because neutrophils are key regulators of intra-luminal survival of cancer cell line and extravasation through their cross-talk with host cells and disseminating cancer cells [28]. Lymphocyte is a non-specific but commonly used as a marker of host immunity [29] [30]. Liver cancer cells could evade the immune surveillance via modulating the key immune cells such as lymphocytes by alpha feto-protein [31] which will affect the prognosis of cancer patients. In recent years, numerous evidences had demonstrated that the lymphocyte count is an independent prognostic marker in various cancers, such as liver, breast, colorectal, lung and others cancers [32] [33] [34] [35] [36]. Besides, lymphocyte count and lymphocyte-white blood cell ratio were also associated with overall survival in advanced cancer patients reported by Zhao [29]. Taken together, these results suggested that a low level of lymphocytes may reflect a poor health status and poor prognosis in advanced cancer 
patients.

NLR is calculated from existing routine blood examination for our patients. An elevated NLR is associated with worse outcomes in many solid tumors, both in early and advanced stage of cancer [37] [38]. By using NLR acting as a biomarker, there is a potential for the identification of early responders and prognostic relevance associated with clinical outcome [8] [39]. We should note that the excessive presence of inflammation and neutrophil which were an indirect risk and can be varied among cancer cell types has the worse impact on the outcome. In our series, three scales of NLR were $\leq 1.62,1.63-2.57$, and $\geq 2.58$ for comparison in our HCC patients. Patients with lower baseline of NLR $\leq 1.62$ were associated with better overall survival. In addition, in other reports, patients with baseline NLR $<5$ had a better median survival of 20.7 months compared to a median overall survival of 7.9 months in patients with baseline NLR $\geq$ 5 specifically in advance cancer patients [37], Cancer patients of poor prognosis were reported if NLR $\geq 5$ in patients with advanced solid tumors treated with PD-1/PD-L1 inhibitors reported by Ameratunga et al. [40]. Concerning base line, there was a statistically significant association between baseline NLR $\geq 3.5$ and immediate progression on 2-month follow-up imaging after TACE patients with progressive disease had a mean of NLR 4.10 compared to stable disease, partial, and complete response had a mean of $2.76,2.72$, and 2.48 respectively in their follow-up results [23]. In our series, the mean survival times were $44.3 \pm$ 3.2 and $24.1 \pm 1.4$ months if the NLR $\leq 1.62$, and $\geq 2.58(\mathrm{P}<0.001)$. Moreover, in another report by using the Cox proportional hazards model showed that NLR $>$ 2.81 was significantly associated with poor overall survival and tumor recurrence in the total or subgroups of patients grading with Barcelona Clinic Liver Cancer (BCLC) stages [41]. Taking together, it is true to demonstrate that a higher NLR resulted in a poorer prognosis reported in similar observations in liver cancer patients [18] [19]. From above studies, the base line of NLR was variable due to their study population included patients in general or specific focus on a specific clinical stage of HCC patients.

It is clear that higher platelet level will result in poorer prognosis because platelet granules contain the greatest abundance of cancer-related factors including, adhesion molecules, growth factors, angiogenic factors, tissue metalloproteinases, chemokines, and immunologic molecules [42] [43] [44]. Even circulating tumor cells may encounter platelet-derived microparticles which may serve to activate the platelets and lead to metastasis [43] [45]. This process is facilitated by adhesion of tumor emboli to the vascular endothelium as well as stimulation of immune cells cytokine and growth factor production among the cellular responses. Therefore, platelets are well suited to serve as facilitators in cancer progression and metastasis which will clearly affect the prognosis of cancer patients [43] [46] [47]. Increased platelet will create an elevated PLR which was associated with reduced overall survival in patients with advanced cancer [48] in addition to HCC [49] [50]. Mean survival was shorter if PLR $\geq 254$ in our series. It is an evidence that either higher NLR or PLR were significantly asso- 
ciated with lymph node metastasis, and poor overall survival in most studies [6] [38] [51]. Taken together, either increased neutrophil and platelet, or decreased lymphocyte will elevate either NLR or PLR. This can be a predictor for the poor prognosis of cancer patients by routine clinical tests. There are some limitations including the applying treatment methods in the patients who follow the treatment guide-line of our hospital cancer registry center. Therefore, there is still a work to be done before using NLR and PLR as validated prognostic markers in clinical settings.

In conclusion, the neutrophil, lymphocyte and platelet are players in cancer growth and have a potential role as predictors of survival in our HCC patients. NLR and PLR are easily obtained in our clinical practice and we should pay more attention to reach a lower ratio for getting a better survival in our patients where possible.

\section{Acknowledgements}

Authors want to express our sincere appreciation of research found supported from Yuan's General Hospital (Research no. 20181107B).

\section{Contribution of Authors}

Study Design: Ker CG.

Data collection: Tong HI, Yang MY, Tseng IT, Chang DM, Chen HY, Ko CM, Chao CY.

Biostastic: Wang BW, Chen YF.

Interpretation and Manuscript: Ker CG.

\section{Conflicts of Interest}

There are no any conflicts of interest of all authors listed in this manuscript or institution or product that is mentioned in the manuscript.

\section{References}

[1] Taiwan MoHaWo (2018) Top 10-Leading Causes of Death in Taiwan 2017. https://wwwmohwgovtw

[2] Torre, L.A., Bray, F., Siegel, R.L., Ferlay, J., Lortet-Tieulent, J. and Jemal, A. (2015) Global Cancer Statistics, 2012. CA: A Cancer Journal for Clinicians, 65, 87-108. https://doi.org/10.3322/caac.21262

[3] Ferlay, J., Steliarova-Foucher, E., Lortet-Tieulent, J., Rosso, S., Coebergh, J.W., Comber, H., et al. (2013) Cancer Incidence and Mortality Patterns in Europe: Estimates for 40 Countries in 2012. European Journal of Cancer (Oxford, England: 1990), 49, 1374-1403. https://doi.org/10.1016/j.ejca.2012.12.027

[4] Itoh, S., Yugawa, K., Shimokawa, M., Yoshiya, S., Mano, Y., Takeishi, K., et al. (2019) Prognostic Significance of Inflammatory Biomarkers in Hepatocellular Carcinoma Following Hepatic Resection. BJS Open, 3, 500-508.

https://doi.org/10.1002/bjs5.50170

[5] Hu, J., Wang, N., Yang, Y., Ma, L., Han, R., Zhang, W., et al. (2018) Diagnostic Value of Alpha-Fetoprotein Combined with Neutrophil-to-Lymphocyte Ratio for 
Hepatocellular Carcinoma. BMC Gastroenterology, 18, Article No. 186. https://doi.org/10.1186/s12876-018-0908-6

[6] Sprinzl, M.F., Kirstein, M.M., Koch, S., Seib, M.L., Weinmann-Menke, J., Lang, H., et al. (2019) Improved Prediction of Survival by a Risk Factor-Integrating Inflammatory Score in Sorafenib-Treated Hepatocellular Carcinoma. Liver Cancer, 8, 387-402. https://doi.org/10.1159/000492628

[7] He, C.B. and Lin, X.J. (2017) Inflammation Scores Predict the Survival of Patients with Hepatocellular Carcinoma Who Were Treated with Transarterial Chemoembolization and Recombinant Human Type-5 Adenovirus H101. PLoS ONE, 12, e0174769. https://doi.org/10.1371/journal.pone.0174769

[8] Wang, D., Bai, N., Hu, X., OuYang, X.W., Yao, L., Tao, Y., et al. (2019) Preoperative Inflammatory Markers of NLR and PLR as Indicators of Poor Prognosis in Resectable HCC. PeerJ, 7, e7132. https://doi.org/10.7717/peerj.7132

[9] Maucort-Boulch, D., de Martel, C., Franceschi, S. and Plummer, M. (2018) Fraction and Incidence of Liver Cancer Attributable to Hepatitis B and C Viruses Worldwide. International Journal of Cancer, 142, 2471-2477.

https://doi.org/10.1002/ijc.31280

[10] Kanda, T., Goto, T., Hirotsu, Y., Moriyama, M. and Omata, M. (2019) Molecular Mechanisms Driving Progression of Liver Cirrhosis towards Hepatocellular Carcinoma in Chronic Hepatitis B and C Infections: A Review. International Journal of Molecular Sciences, 20, 1358. https://doi.org/10.3390/ijms20061358

[11] Coussens, L.M. and Werb, Z. (2002) Inflammation and Cancer. Nature, 420, 860-867. https://doi.org/10.1038/nature01322

[12] Mantovani, A., Savino, B., Locati, M., Zammataro, L., Allavena, P. and Bonecchi, R. (2010) The Chemokine System in Cancer Biology and Therapy. Cytokine \& Growth Factor Reviews, 21, 27-39. https://doi.org/10.1016/j.cytogfr.2009.11.007

[13] Coffelt, S.B., Wellenstein, M.D. and de Visser, K.E. (2016) Neutrophils in Cancer: Neutral No More. Nature Reviews Cancer, 16, 431-446. https://doi.org/10.1038/nrc.2016.52

[14] Rollins, B.J. (2006) Inflammatory Chemokines in Cancer Growth and Progression. European Journal of Cancer (Oxford, England: 1990), 42, 760-767. https://doi.org/10.1016/j.ejca.2006.01.002

[15] Ludlam, C.A. (1980) The assessment of Platelet Function in Vivo by Measurement of Beta-Thromboglobulin, Platelet Factor 4 and Platelet Survival. Artery, 8, 470-474.

[16] Dubernard, V., Arbeille, B.B., Lemesle, M.B. and Legrand, C. (1997) Evidence for an Alpha-Granular Pool of the Cytoskeletal Protein Alpha-Actinin in Human Platelets That Redistributes with the Adhesive Glycoprotein Thrombospondin-1 during the Exocytotic Process. Arteriosclerosis, Thrombosis, and Vascular Biology, 17, 2293-2305. https://doi.org/10.1161/01.ATV.17.10.2293

[17] Yang, H.J., Guo, Z., Yang, Y.T., Jiang, J.H., Qi, Y.P., Li, J.J., et al. (2016) Blood Neutrophil-Lymphocyte Ratio Predicts Survival after Hepatectomy for Hepatocellular Carcinoma: A Propensity Score-Based Analysis. World Journal of Gastroenterology, 22, 5088-5095. https://doi.org/10.3748/wjg.v22.i21.5088

[18] Rashtak, S., Ruan, X., Druliner, B.R., Liu, H., Therneau, T., Mouchli, M., et al. (2017) Peripheral Neutrophil to Lymphocyte Ratio Improves Prognostication in Colon Cancer. Clinical Colorectal Cancer, 16, 115-123e3. https://doi.org/10.1016/j.clcc.2017.01.008

[19] Graziano, V., Grassadonia, A., Iezzi, L., Vici, P., Pizzuti, L., Barba, M., et al. (2019) Combination of Peripheral Neutrophil-to-Lymphocyte Ratio and Platelet-to-Lymp- 
hocyte Ratio Is Predictive of Pathological Complete Response after Neoadjuvant Chemotherapy in Breast Cancer Patients. Breast (Edinburgh, Scotland), 44, 33-38. https://doi.org/10.1016/j.breast.2018.12.014

[20] Deng, M., Ma, X., Liang, X., Zhu, C. and Wang, M. (2017) Are Pretreatment Neutrophil-Lymphocyte Ratio and Platelet-Lymphocyte Ratio Useful in Predicting the Outcomes of Patients with Small-Cell Lung Cancer? Oncotarget, 8, 37200-37207. https://doi.org/10.18632/oncotarget.16553

[21] Tas, M., Yavuz, A., Ak, M. and Ozcelik, B. (2019) Neutrophil-to-Lymphocyte Ratio and Platelet-to-Lymphocyte Ratio in Discriminating Precancerous Pathologies from Cervical Cancer. Journal of Oncology, 2019, Article ID: 2476082. https://doi.org/10.1155/2019/2476082

[22] Chen, K., Zhan, M.X., Hu, B.S., Li, Y., He, X., Fu, S.R., et al. (2018) Combination of the Neutrophil to Lymphocyte Ratio and the Platelet to Lymphocyte Ratio as a Useful Predictor for Recurrence Following Radiofrequency Ablation of Hepatocellular Carcinoma. Oncology Letters, 15, 315-323. https://doi.org/10.3892/ol.2017.7291

[23] Cruz, J.C., Watchmaker, J.M., Albin, M.M., Wang, L., Wu, G., Baker, J.C., et al. (2019) Neutrophil/Lymphocyte Ratio Predicts Increased Risk of Immediate Progressive Disease following Chemoembolization of Hepatocellular Carcinoma. Jour nal of Vascular and Interventional Radiology. JVIR, 30, 1887-1892.

https://doi.org/10.1016/j.jvir.2019.08.001

[24] Chen, Y., Wang, W., Zhang, X., Yu, X., Xi, K., Wen, Y., et al. (2018) Prognostic Significance of Combined Preoperative Platelet-to-Lymphocyte Ratio and Lymphocyte-to-Monocyte Ratio in Patients Undergoing Surgery with Stage IB Non-Small-Cell Lung Cancer. Cancer Management and Research, 10, 5411-5422. https://doi.org/10.2147/CMAR.S177320

[25] Ocana, A., Nieto-Jiménez, C., Pandiella, A. and Templeton, A.J. (2017) Neutrophils in Cancer: Prognostic Role and Therapeutic Strategies. Molecular Cancer, 16, 137. https://doi.org/10.1186/s12943-017-0707-7

[26] Swierczak, A., Mouchemore, K.A., Hamilton, J.A. and Anderson, R.L. (2015) Neutrophils: Important Contributors to Tumor Progression and Metastasis. Cancer and Metastasis Reviews, 34, 735-751. https://doi.org/10.1007/s10555-015-9594-9

[27] Dumitru, C.A., Lang, S. and Brandau, S. (2013) Modulation of Neutrophil Granulocytes in the Tumor Microenvironment: Mechanisms and Consequences for $\mathrm{Tu}$ mor Progression. Seminars in Cancer Biology, 23, 141-148. https://doi.org/10.1016/j.semcancer.2013.02.005

[28] Spiegel, A., Brooks, M.W., Houshyar, S., Reinhardt, F., Ardolino, M., Fessler, E., et al. (2016) Neutrophils Suppress Intraluminal NK Cell-Mediated Tumor Cell Clearance and Enhance Extravasation of Disseminated Carcinoma Cells. Cancer Discovery, 6, 630-649. https://doi.org/10.1158/2159-8290.CD-15-1157

[29] Zhao, W., Wang, P., Jia, H., Chen, M., Gu, X., Liu, M., et al. (2017) Lymphocyte Count or Percentage: Which Can Better Predict the Prognosis of Advanced Cancer Patients Following Palliative Care? BMC Cancer, 17, 514. https://doi.org/10.1186/s12885-017-3498-8

[30] Saleh, R.R., Peinado, P., Fuentes-Antras, J., Perez-Segura, P., Pandiella, A., Amir, E., et al. (2019) Prognostic Value of Lymphocyte-Activation Gene 3 (LAG3) in Cancer: A Meta-Analysis. Frontiers in Oncology, 9, 1040. https://doi.org/10.3389/fonc.2019.01040

[31] Ashokachakkaravarthy, K. and Pottakkat, B. (2020) Mitotic Quiescence in Hepatic 
Cancer Stem Cells: An Incognito Mode. Oncology Reviews, 14, 452. https://doi.org/10.4081/oncol.2020.452

[32] Cho, O., Oh, Y.T., Chun, M., Noh, O.K. and Lee, H.W. (2016) Radiation-Related Lymphopenia as a New Prognostic Factor in Limited-Stage Small Cell Lung Cancer. Tumour Biology: The Journal of the International Society for Oncodevelopmental Biology and Medicine, 37, 971-978. https://doi.org/10.1007/s13277-015-3888-y

[33] Tredan, O., Manuel, M., Clapisson, G., Bachelot, T., Chabaud, S., Bardin-dit-Courageot, C., et al. (2013) Patients with Metastatic Breast Cancer Leading to CD4 ${ }^{+} \mathrm{T}$ Cell Lymphopaenia Have Poor Outcome. European Journal of Cancer (Oxford, England: 1990), 49, 1673-1682. https://doi.org/10.1016/j.ejca.2012.11.028

[34] Liang, L., Zhu, J., Jia, H., Huang, L., Li, D., Li, Q., et al. (2016) Predictive Value of Pretreatment Lymphocyte Count in Stage II Colorectal Cancer and in High-Risk Patients Treated with Adjuvant Chemotherapy. Oncotarget, 7, 1014-1028. https://doi.org/10.18632/oncotarget.5835

[35] Wild, A.T., Ye, X., Ellsworth, S.G., Smith, J.A., Narang, A.K., Garg, T., et al. (2015) The Association between Chemoradiation-Related Lymphopenia and Clinical Outcomes in Patients with Locally Advanced Pancreatic Adenocarcinoma. American Journal of Clinical Oncology, 38, 259-265. https://doi.org/10.1097/COC.0b013e3182940ff9

[36] Li, C., Wen, T.-F., Yan, L.-N., Li, B., Yang, J.-Y., Xu, M.-Q., et al. (2013) Scoring Selection Criteria Including Total Tumour Volume and Pretransplant Percentage of Lymphocytes to Predict Recurrence of Hepatocellular Carcinoma after Liver Transplantation. PLOS ONE, 8, e72235. https://doi.org/10.1371/journal.pone.0072235

[37] Li, M., Spakowicz, D., Burkart, J., Patel, S., Husain, M., He, K., et al. (2019) Change in Neutrophil to Lymphocyte Ratio during Immunotherapy Treatment Is a Non-Linear Predictor of Patient Outcomes in Advanced Cancers. Journal of Cancer Research and Clinical Oncology, 145, 2541-2546. https://doi.org/10.1007/s00432-019-02982-4

[38] Zhang, L.X., Wei, Z.J., Xu, A.M. and Zang, J.H. (2018) Can the Neutrophil-Lymphocyte Ratio and Platelet-Lymphocyte Ratio Be Beneficial in Predicting Lymph Node Metastasis and Promising Prognostic Markers of Gastric Cancer Patients? Tumor Maker Retrospective Study. International Journal of Surgery (London, England), 56, 320-327. https://doi.org/10.1016/j.ijsu.2018.06.037

[39] Taussig, M.D., Irene Koran, M.E., Mouli, S.K., Ahmad, A., Geevarghese, S., Baker, J.C., et al. (2017) Neutrophil to Lymphocyte Ratio Predicts Disease Progression Following Intra-Arterial Therapy of Hepatocellular Carcinoma. HPB: The Official Journal of the International Hepato Pancreato Biliary Association, 19, 458-464. https://doi.org/10.1016/j.hpb.2017.01.013

[40] Ameratunga, M., Chenard-Poirier, M., Moreno Candilejo, I., Pedregal, M., Lui, A., Dolling, D., et al. (2018) Neutrophil-Lymphocyte Ratio Kinetics in Patients with Advanced Solid Tumours on Phase I Trials of PD-1/PD-L1 Inhibitors. European Journal of Cancer (Oxford, England: 1990), 89, 56-63.

https://doi.org/10.1016/j.ejca.2017.11.012

[41] Lu, S.D., Wang, Y.Y., Peng, N.F., Peng, Y.C., Zhong, J.H., Qin, H.G., et al. (2016) Preoperative Ratio of Neutrophils to Lymphocytes Predicts Postresection Survival in Selected Patients with Early or Intermediate Stage Hepatocellular Carcinoma. Medicine, 95, e2722. https://doi.org/10.1097/MD.0000000000002722

[42] Suner, A., Carr, B.I., Akkiz, H., Karakulah, G., Uskudar, O., Yalcin, K., et al. (2019) C-Reactive Protein and Platelet-Lymphocyte Ratio as Potential Tumor Markers in 
Low-Alpha-Fetoprotein Hepatocellular Carcinoma. Oncology, 96, 25-32. https://doi.org/10.1159/000492473

[43] Menter, D.G., Kopetz, S., Hawk, E., Sood, A.K., Loree, J.M., Gresele, P., et al. (2017) Platelet "First Responders" in Wound Response, Cancer, and Metastasis. Cancer and Metastasis Reviews, 36, 199-213. https://doi.org/10.1007/s10555-017-9682-0

[44] Menter, D.G., Tucker, S.C., Kopetz, S., Sood, A.K., Crissman, J.D. and Honn, K.V. (2014) Platelets and Cancer: A Casual or Causal Relationship: Revisited. Cancer and Metastasis Reviews, 33, 231-269. https://doi.org/10.1007/s10555-014-9498-0

[45] Green, D.L. and Karpatkin, S. (2009) Effect of Cancer on Platelets. Cancer Treatment and Research, 148, 17-30. https://doi.org/10.1007/978-0-387-79962-9_2

[46] Wojtukiewicz, M.Z., Sierko, E., Hempel, D., Tucker, S.C. and Honn, K.V. (2017) Platelets and Cancer Angiogenesis Nexus. Cancer and Metastasis Reviews, 36, 249-262. https://doi.org/10.1007/s10555-017-9673-1

[47] Xu, X.R., Zhang, D., Oswald, B.E., Carrim, N., Wang, X., Hou, Y., et al. (2016) Platelets Are Versatile Cells: New Discoveries in Hemostasis, Thrombosis, Immune Responses, Tumor Metastasis and Beyond. Critical Reviews in Clinical Laboratory Sciences, 53, 409-430. https://doi.org/10.1080/10408363.2016.1200008

[48] Li, B., Zhou, P., Liu, Y., Wei, H., Yang, X., Chen, T., et al. (2018) Platelet-to-Lymphocyte Ratio in Advanced Cancer: Review and Meta-Analysis. Clinica Chimica Acta; International Journal of Clinical Chemistry, 483, 48-56. https://doi.org/10.1016/j.cca.2018.04.023

[49] Zheng, J., Cai, J., Li, H., Zeng, K., He, L., Fu, H., et al. (2017) Neutrophil to Lymphocyte Ratio and Platelet to Lymphocyte Ratio as Prognostic Predictors for Hepatocellular Carcinoma Patients with Various Treatments: A Meta-Analysis and Systematic Review. Cellular Physiology and Biochemistry: International Journal of EXperimental Cellular Physiology, Biochemistry, and Pharmacology, 44, 967-981. https://doi.org/10.1159/000485396

[50] Ma, W., Zhang, P., Qi, J., Gu, L., Zang, M., Yao, H., et al. (2016) Prognostic Value of Platelet to Lymphocyte Ratio in Hepatocellular Carcinoma: A Meta-Analysis. Scientific Reports, 6, Article No. 35378. https://doi.org/10.1038/srep35378

[51] Shiraki, T., Ishizuka, M., Kubota, K., Kato, M., Matsumoto, T., Mori, S., et al. (2019) An Elevated Neutrophil-to-Lymphocyte Ratio Predicts a Poor Postoperative Survival in Primary Hepatocellular Carcinoma Patients with a Normal Preoperative Serum Level of Alpha-Fetoprotein. Surgery Today, 49, 661-669. https://doi.org/10.1007/s00595-019-01781-1 